\title{
Humans and Animals: Issues in Ethics
}

\author{
A Nettuno 1 \\ ${ }^{1}$ Sapienza University of Rome. Department of Philosophy
}

submitted: Aug 31, 2017, accepted: Sep 21, 2017, EPub Ahead of Print: Oct 12, 2017, published: Dec 31, 2017

Conflict of interest: None

DOI: 10.24019/jtavr.33 - Corresponding author: Dr. Alberto Nettuno, alberto.nettuno@uniroma1.it

(C) 2017 Fondazione Vasculab impresa sociale ONLUS. All rights reserved.

\begin{abstract}
In the last decades of the twentieth century the question of relationship between humans and animals has become a very important area of Applied Ethics. Indeed, starting from seventies the specism (considered as form of discriminatory of non-human animals) has been put to the center of moral reflection mainly thanks to Peter Singer and Tom Regan. The debate is still in progress and have been added other philosophical positions, as an example the Ethics of care (Rosalynd Hursthouse) and Egalitarianism (Ingmar Persson). Therefore, Pollo's text represents a valuable contribution of sentimentalism ethics to modern Animal ethics. The author's analysis does not want to be exhaustive, but it want to be instrument to reflect on ethical questions between humans and animals.
\end{abstract}

Keywords Animal ethics, Moral sentimentalist, Animal welfare, animal Testing, Moral progress

The privileged object of this work ${ }^{1}$, as defined in a programmatic way in the introduction, focuses on the relations human beings have with animals (not humans) in daily life. Pollo's text, that is part of the sentimentalist tradition in ethics, aims at being a contribution to the development of Animal Ethics in common life. The book is dedicated to Eugenio Lecaldano, who is among the major exponents of this tradition in the Italian philosophical panorama. In complete agreement with this tradition, the author wants to investigate how feelings, simpathy and imagination can develop and the maintain moral reflection on the interaction between humans and animals. The book does this through a dense and constant comparison with the important theoretical and regulatory frameworks defined by Peter Singer and Tom Regan, the pioneers of modern antispecism.
Umani e animali, therefore, finds its place across the Italian and international specialized debate and it does so suggesting an alternative and, at the same time, fascinating point of view. Our moral reflection towards animals needs to proceed in constant agreement with everyday experience, since this latter should be given priority compared to the theoretical philosophical reflection. This methodological assumption represents the central theme of the essay and it embodies its main turning point. This type of framework, however, as advised by the author himself, does not want to suggest that the theoretical rationalistic analyses must be abandoned, but wants to affirm that the two need to be integrated by a more immediate dimension, as close as possible to what we are as human beings, belonging to the Homo Sapiens species.

In this context, we find the most performative aspect of the book: the variety of relationships we establish with animals and the daily direct and indirect interactions that we maintain with them are an integral part of our cultural and biological identity and therefore they should represent the starting point for the moral reflection on Animal Ethics.

The text can be ideally divided into three parts that correspond to the three objectives the author resolves to achieve: to offer an informative picture of some "facts" concerning the relationships between Homo sapiens and the other animal species (Ch 1); to illustrate how the research field of contemporary Animal Ethics originated through the analysis of some theoretical positions of the past (Ch 2, 3 and 4); finally, to discuss, from an alternative point of view (compared to the dominant concept), three big categories of interactions between humans and animals (nutrition $\mathrm{Ch} 5$; use of animals for biomedical research Ch. 6; safeguard of wild animals Ch. 7). 


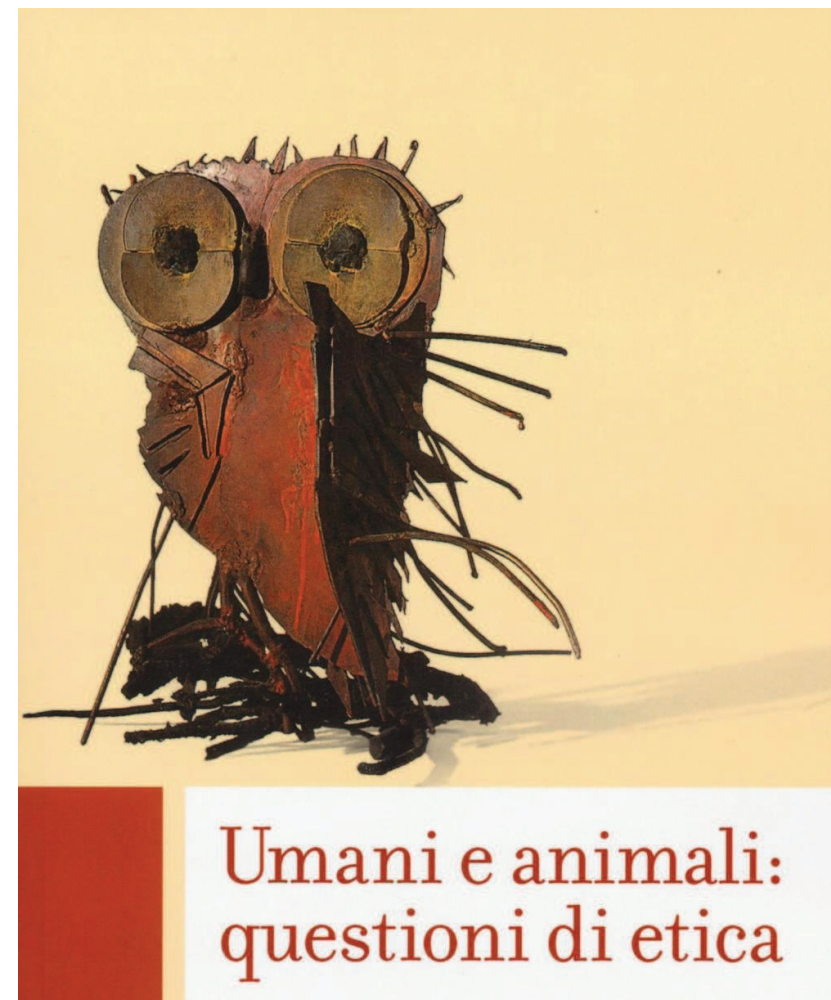

Simone Pollo

Garocci editore @ Quality Paperbacks domestication: it is through this experience that human beings would have started to develop the ability to "understand" animals; this would have initiated a path that, through genetic transmission, lead to the development of the ability to understand others' minds, with all the ethical and historical implications entailed.

Another fundamental point of Pollo's analysis is the acquisition of Darwin's theory of evolution, interpreted as the theoretical-empirical corpus denominated "New synthesis" ${ }^{2}$. According to the author, this theory represents the "turning point" that works as and create a divide between a "before" and an "after" in the field of Animal Ethics. Indeed, starting from Darwin, the ontologicallybased approach proposed by René Descartes on the discontinuity between animals and humans will become unsustainable. This assumption is one of the two "theoretical requirements" the author defines along the book.

The second is the need drawing attention to the variety of positions presented in the first place by Darwin himself and represents the second objective the author is determined to achieve. Comparing thinkers like Aristotle, Saint Thomas Aquinas, Kant and Porphyry of Tyre, the author demonstrates how reflection on the relationships with animals is well established in the tradition of Western thought and how Animal Ethics, as it is structured today, represents the last chapter of a richly diversified path that has its roots in the past ( in regards to this, Pollo also reminds us that Animal Ethics has developed in conjunction with the arrival of the feminist and anti-racist movements of the ' 60 s and ' 70 s).

However, the most radical thought/critique is found

Figure 1 - Simone Pollo. Umani e animali: questioni di etica.

As for the first point, the idea (or the fact) that the author wants to support is contained in the following formula: "we are humans thanks to the animals" (p.17).

Through an excursus of the evolutionary and historical path of Homo Sapiens, the author provides solid proof supporting the idea that our form-of-life, as it is today, is inextricably connected to the life of non-human animals. This "fact" should be analysed, in Pollo's perspective, starting from the central mechanisms of "ecosystem" and "coevolution". The interdependence of the living species and their interactions, that lead to a continuous modification of the specific traits in a continuous process of reciprocal adaptation, are at the base of the genetic characteristics that we can observe in human beings nowadays. Human beings, hence, are this way because during their biological evolution they have been interacting with other non-human animals and they have been breeding them, eating them, etc. However, the author sees a possible fundamental turning point for evolution mainly in the old practice of in the two following chapters (third and fourth) and it deals with the core of the anti-speciesist ideas proposed by Peter Singer, Tom Regan and Gary Francione. Pollo offers and alternative perspective to the theoretical normative ones of the two fathers of Animal Liberation. Where Animal Liberation affirms that "rationality" must take on a central role in the development on Animal Ethics, Pollo presents a sentimentalist perspective that places emotions and sympathy at the centre of moral life. It is a "sentimentalist anti-anthropocentrism", conscious of the fact that change is possible only from a human point of view, with its potentialities and limits. Indeed, the rationalistic ethics of Singer and Regan on its own might not be enough to overcome those obstacles inherent to human beings that were well highlighted by moral psychology: the partial inability of human beings to follow the rules laid out in theory and the fact that the cultural context in which we live and our biological structure itself are profoundly linked (because inherited) to the life of other animal species. For this reason, Pollo's perspective moves from the "bottom" of experience and from its "inside" and aims to underline how 
the forms of interactions with other species can become the centre of moral reflection.

Starting from this focal point, Pollo criticizes analyse Gary Francione's concept, according to whom all relationships with animals (including domestic ones) must be considered as forms of exploitation and slavery and should therefore be suppressed. The risks coming from such a view, according to Pollo, are the following: under defining the relevant aspects of moral experience and, as in the monist theories of Singer and Regan, leaving little space to the variety of possible situations that can lead human beings to empathize with the other sentient beings.

At this point in the text, after expressing his method and the direction he wants to give to his reflection on Animal Ethics (following the one proposed/developed by the neo-Humean philosopher Mary Midgley), the author takes on the analysis of three big categories of interaction between humans and animals (this is the third purpose of the book). Consistent with his theoretical approach, the discussion will not end with argumentations in favour of animal liberation: indeed, it is important to remember that Pollo's contribution wants to be an opportunity to reflect on the ways "human beings shape their behaviour towards animals in the different contexts in which they come into contact with them in their daily life" (p.84).

The first big category the author focuses on is the use of animals for food: the essential precondition for every discussion on morality in this background concerns our biological and cultural inheritance, in which the presence of food of animal origin is "inevitable" (p.89). After analysing Singer and Regan's positions on the subject, respectively based on the Utilitarian paradigm and on the Rights theory, Pollo's analysis emphasizes the idea that the public acknowledgment of some form of rights (in this case for animals) represents the end point of moral reflections and transformations that act, first of all, on the moral agent at an individual level. Therefore, referring to John Mill's concept of "self-perfectioning", Pollo's idea of challenging nutritional behaviours presents itself "as a criticism on one's own identity and in the possibility of recognising oneself in those transmitted habits" (p.97). The characteristics that need to be nurtured are the following: attention to one's own personality, questioning of oneself and inclination towards moral growth. These, indeed, can expand moral recognition of animals, leading to an informed and lasting choice towards a vegan or vegetarian diet.

A very interesting aspect of this analysis is the fact that it intersects with feminist reflection and the Gender studies. Referring to Carol Adam's analysis of philosophy (2013), the author states that the culinary culture in our society includes some elements of male sexism and promotes forms of gender discrimination (p.100). This position is confirmed by the important study by Erika
Cudworth who emphasizes two main turning points relating to carnivorous diets. The first is the presence, in western society, of a type of hierarchy of food in which red meat consumption is usually associated with manliness while white meat and dairy products are usually related to femininity. The second point concerns the way in which we prepare meat: roasting or grilling red meat, for example, is the favourite cooking method for men because the meat remains rare, recalling those myths that narrate how manliness and strength come from the animal blood. Boiling or stewing meat, on the contrary, seems to remind a more domestic and feminine context ${ }^{3}$. In any case, Pollo's intention is to underline the transformative potential that a vegetarian choice could prompt on ourselves and, therefore, on our environment and society.

Our interactions with "wild animals", that is those animals "whose existence does not depend on steady processes of domestication and selection" (p.118), represent another aspect of our life that is discussed by the author. While talking about nutrition, the discussion proceeded on the level of individual behaviour where the idea of animal welfare turned out to be the most functional. When the attention shifts to the interaction with wild animals, the level of analysis is that of social behaviour and the reflection revolves around the idea of "respect", considered as "moral acknowledgment and approval of the individuality and freedom of other subjects" (p.122). Indeed the author criticizes the dominant views of Martha Nussbaum on justice and of Singer on utilitarianism for not having fully absorbed the lesson coming from the Darwinian theory. This would be the essential missing part in the two theoretical positions analysed by the author that made them move, according to Pollo, towards the field of the metaphysical foundations of Judeo-Christian anthropocentrism, even if not sharing with it its ontological presuppositions. The acquisition of the theory of evolution, instead, would place human beings in a non-central position compared to the other sentient beings (and to the "natural" world) and, as a consequence, would lead society to make some critical considerations towards the practices of "preservation" of the ecosystems and of "wild" animals that originated precisely from the concept of "respect". On the theoretical level, a comparison between Pollo's approach and that of some bioethicists in favour of moral enhancement of non-human animals would be intellectually stimulating $^{4}$.

The use of animals for biomedical research is the third area of interaction discussed in the text and, undoubtedly, represents the most sensitive one although, as demonstrated through data by the author himself, it is the one with the smallest number of animals involved and especially considerably lower than, for example, the number of those used for food.

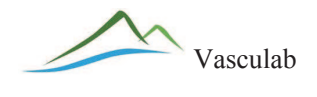


The use of animals for experimentation is an ancient practice dating back to the VI century a.C., that is when science as such was born in classical Greece. This practice is well established in the history of scientific research: this is the starting point, according to the author, for the analysis of its moral acceptability. Medicine has indeed reached extraordinary results in the last centuries, mainly thanks to experimentations on animals. Our form of life, therefore, is deeply linked to medical science and its results. Moreover, if referring to food and to the "preservation" of wildlife, the theoretical and practical path is definitely smoother (in principle, we can all do without steaks, creams, etc) and it becomes more difficult when what is at stake are the interests of life and death of human beings.

Reaching the core of the philosophical reflection in this specific context, Pollo discusses Singer's position. In accordance with the utilitarian approach, Singer's perspective shows how, in specific circumstances, the advantage of a certain number of sentient beings belonging to any species can justify the use of other sentient beings for experimental purposes. Pollo also discusses Regan's theory of rights that, on the contrary, categorically denies the morality of the use of sentient beings for this purpose. In both instances, the aim is to argue "in favour of a radical reform of science, suppressing de facto any invasive use of animals" (p.170). At this point, the author discusses if and how these approaches in the field of biomedical experimentation can actually prove to be effective. Whilst the approach of "perfect equality", peculiar to Regan's theory of rights, cannot bring convincing results, Singer's utilitarian approach, on the contrary, turns out to be the one that most complies with the changes in animal testing and therefore with the search of alternative methods not requiring the use of animals, a reduction in number of animals involved and a bigger attention to their welfare (as expected in the "model of the three Rs"). However, this approach presents some limits that are well described by the author, among which some stand out: the "conservation of the preferences of the species" and the uncertainty of positive outcomes in the ongoing research (pp. 110-111).

To limit an excessive "simplification" of these positions, Pollo's, in accordance with his chosen approach, places the analysis in the reality of everyday research. Indeed, the curve outlined by the author is in agreement with the genealogy of a Humean - conventionalist type of society, according to which sociality is built around forms of cooperation and reciprocity among humans and justice is the result of the stratification of regulations that are not always intentional (p. 109). This means that social critical responses to animal testing ("vivisection" is an unsuitable term for the contemporary context) will necessarily have to interact with the "specific contexts", that is with the scientific community. Concepts like "trust", "authority" and "truth" are an essential part of scientific research and, therefore, Pollo states that ethics does not have to "moralize" science, in opposition to what Singer and Regan's monist theories would support. The inclusion of animals in a broader sphere of moral reflection and the reconsideration of their use in research cannot be dictated by external regulations (such as European legislations, etc.), but these latter should be considered as sources for the promotion of moral reflection itself and of animal welfare, and they should be made available to researchers and technicians, that is to those who work in this context on a daily basis.

The effectiveness of this type of approach is confirmed, for example, in the case of the 27 macaques destined to research and recently released by the Health Research Consortium of Padova. The active role of the Consortium itself, together with the University of Padova and the Zooprophyilactic Institute of Venice, in the release of the animals has also been publicly praised by $\mathrm{LAV}^{5}$, a particularly active animal rights association that fully opposes the use of animals for research.

In the conclusion of the book the author tackles the issue of "moral progress" in our society. The notion of "moral progress" is undoubtedly problematic and, as explained by Pollo, there are two ways to interpret it. The first takes inspiration from Dale Jamieson's formulation and here we can find the rationalistic concepts analysed in the previous pages of the text. According to this interpretation, "moral progress" would represent "the realization, in this world, of the process of accumulation of a particular value or good" (p.131). The second possible interpretation is the one outlined by the author himself in a previous article ${ }^{6}$ and described as "the increase of moral reflexive skills in humans" (p.131). In this latter interpretation there is less stress on the individual adaptation to a normative model and more attention is being placed, instead, to the richness of moral experience in daily life. The two concepts, however, are not alternatives, the author says, but they need to intertwine and complement each other in order to contain the constant risk of falling into "moralism".

As a whole, in conclusion, Pollo's contribution to Animal Ethics represents a useful instrument of reflection for philosophers, animal rights activists, researchers and for all those interested in the ethical debate of the relations between humans and animals. 


\section{References}

1) Pollo S. Umani e animali: questioni di etica. [Humans and Animals: Issues in Ethics]. Roma: Carocci Ed; 2016. ISBN 978-88-430-8465-4.

2) Mayr E, Provine WB. The evolutionary synthesis. Harvard UP, Cambridge, 1980.

3) Cudworth E. The recipe for love Continuities and changes in the sexual politics of meat. Journal for critical animal studies, JCAS 2010;8(4):78-100.
4) Chan S. Should we enhance animals? Journal of Medical Ethics 2009;35:678-83.

5) LAV report of 20/07/2017. Available at http:/lav.it/news/ padova-salvi-27-macachi, at the date of Oct 07, 2017.

6) Pollo S. Progresso scientifico e progresso morale. Sentimentalismo, oggettività e scienza [Scientific progress and moral progress. Sentimentalism, objectiveness and science]. Rivista di filosofia 2016;CVII(2):219-39. 